\title{
Consumption based on Mindful Mindset: A Solution to Plastic Pollution
}

\author{
Kannikar Khaw-ngern ${ }^{1}$, Lampong Klomkul ${ }^{2}$, Prateep Peuchthonglang ${ }^{3}$, Chainarong Khaw-ngern ${ }^{4}$ \\ ${ }^{1}$ Faculty of Buddhism, Mahachulalongkornrajavidyalaya University, \\ ${ }^{2}$ Faculty of Education, Mahachulalongkornrajavidyalaya University, \\ ${ }^{3}$ Faculty of Business Administration and Liberal Arts, Rajamangala University of Technology Lanna, \\ ${ }^{4}$ Faculty of Humanities, Mahachulalongkornrajavidyalaya University \\ ${ }^{1}$ kannikar.khaw@gmail.com, ${ }^{2}$ research.mcu@gmail.com, ${ }^{3}$ Khun_Jedrin@ hotmail.com, ${ }^{4}$ chainarong.kha@mcu.ac.th
}

\begin{abstract}
Plastic pollution is one of the most visible problems in many regions, especially in developing Asian and African countries, which lack of proper garbage collection systems. Everyone in societies need to work together in dealing with plastic pollution. The purpose of this article is to examine how plastic pollution effects human and environmental well-being, to study the influence of mindfulness on consumption behaviours, and to explore how mindful consumption contributes to the reduction of plastic pollution and brings ecological sustainability. Documentary study and literature review were used for data collection. Plastic pollution has become one of the most serious problems around the world, especially during the spread of COVID-19 due to the increase of single-use plastic waste. Results showed that plastic pollution causes many major long-term effects to human and ecosystem including the food chain changes, contagious diseases and respiratory diseases, polluted land, water, and air due to toxic chemicals residue. With mindful mindset, individuals will have a sense of caring and thinking about the future and the consequences of their actions towards themselves, community, and nature, so they behave and make decisions with the aim of increasing a consumer's personal, economic, and social well-being to an optimal level. Mindful consumption, consciousness in thought and behavior about the implications and consequences of consumption, is a consumption framework guiding consumers to make their choices with the care of self and community while conserving environmental, personal and economic well-being. Thus, mindful consumption can be considered as sustainable consumption pattern and it can make a great contribution to reduction of plastic pollution and sustainable development.
\end{abstract}

Keywords

Mindful Mindset, Mindful Consumption, Plastic Pollution, Sustainable Consumption

Article Received: 10 August 2020, Revised: 25 October 2020, Accepted: 18 November 2020

\section{Introduction}

Global growth is set to continue. Plastics consumption increases as economies develop and begin using them in a range of products and consumer goods. Our analysis suggests that by 2050 , global plastics production would double to over 800 million tonnes per year. If made with today's fossil feedstock, global plastics production would then require $900 \mathrm{Mt}$ of oil per year, more than the European Union uses today, and $23 \%$ of total global oil use in a $2^{\circ} \mathrm{C}$ scenario [1]. By the end of the century, plastics consumption would need to rise further, to 1345 million tonnes per year, more than four times today's levels. By any measure, plastics therefore are a major determinant of future fossil fuel use and hence also of carbon dioxide (CO2) emissions [2].

In many developing countries, especially those in Asia and Africa, plastic pollution is one of the most visible problems due to lack of proper garbage collection systems. But the developed world, especially in countries with low recycling rates, also has trouble of improperly collecting discarded plastics. Plastic waste, thus, has become such a widely spread problem that there are urgent need to write a global treaty negotiated by the United Nations. It has become one of the most pressing environmental issues, as rapidly increasing production of disposable plastic products overwhelms the world's ability to deal with them.

Plastics is the problem not only for municipality officials, region administrators, or our government, but it is the problem for everyone to look into and ask, "Hmm, what can I do about this problem?" That means everyone in societies should consider and work together in reducing plastics consumption, plastic waste, and plastic pollution by thinking it over before buying or using plastics. To always stay aware of plastic problems means one needs to be mindful of the plastic problems before making decision on buying, using, or throwing away plastic items. Consumption with mindfulness or mindful consumption is in the essence of consumers will become more mindful about what they buy, why they are buying it, how it was made and whether it causes waste and pollution to our communities. Mindfulness, when being applied to consumption habits, can be an effective tool in dealing with plastics pollution.

\section{Plastic Pollution}

Plastics have changed our world. In our society, plastic has been used in various types of products from fresh food packages for keeping freshness and hygiene to essential uses like medical supplies, automation and electronics. However, plastics usage has exploded at such a rate that the infrastructure needed to manage its waste has not kept pace. This is our biggest challenge and it is a serious and complex issue which no one can solve alone. It is a journey that will involve everyone in every community to work together to end plastic waste in the environment.

Plastics provide us great deal of benefits for health, safety, and they are used for improving living quality around the world in both developing and developed countries around the world, but it is unwanted for in our environmental systems; land, rivers, seas, and oceans. Plastic production has been increasing by over 400 million tons 65 years, from 1950-2015. And by 2050, it is expected to be double [3]. In each year, about 8 million tons of plastic wastes are released 
to the oceans. It can cause significant harm to the environment in the form of polluted air, water, and land due to its content of toxic pollutants.

It is obvious that this amount of a material which does not break down rapidly can ruin the natural environment. It will lead to long-term issues for plants, animals, and people. Plastic pollution causes many major long-term effects including the Food Chain Changes. It affects the world's tiniest organisms such as phytoplankton and zooplankton, which together form the base of oceanic food chain. When these organisms become poisoned due to plastic ingestion, this causes problems for the larger animals that depend on them for food. Microplastics can also accumulate in fish, birds and other marine life. As microplastics can take over 400 years to break down, their amount in the sea and sea animals will continue to accumulate, making the problem worse over time.

Plastic pollution is also linked to human well-being. Plastic debris results in a loss in recreational value (e.g. through beach litter), potentially depleting psychological restoration of humans in natural environments. In this regard, behavioural studies have shown that marine litter can undermine the psychological benefits normally experienced at the coast. More direct impacts on human health and safety may occur via accidents resulting in costs for medical treatment. In terms of pest control, it is well known that plastic litter provides breeding sites for pathogentransmitting insects, therefore facilitate the spread of diseases, for instance, dengue virus, for instance. Moreover, plastic pollution inflicts a loss on the intrinsic value of nature, thus depletes important cultural services provided by an ecosystem. Eventually, this also touches on larger moral issues concerning the relationship between societies and the environment [4].

\section{The Effects Of Plastic Pollution On Human Health}

Plastic pollution can lead to many health hazards, including physical, chemical, and biological factors that can have negative impacts on our health in short term and long term. For many years, plastic has accumulated and releases harmful chemicals, and it breaks down into small pieces causing extreme discomfort to the animals. Bioaccumulation of plastic inside animals is one of the most recent effects of plastic pollution as it. After their death, the body might decompose but the plastic fragments may remain as a threat to other animals. Besides, blockage due to plastic accumulation may form shelters for the breeding of mosquitoes and other harmful vectors insects, which might cause numerous diseases in humans.

Improper plastic disposal, burning, is also another significant factor leading to contamination of the atmosphere because toxic chemicals are released into the air, leading to air pollution. Burning process requires laborers, who are at the risk of developing skin and respiratory problems due to inhalation of recycling toxic chemicals. Plastics are also carried by wind and deposited from one place to another, increasing the land litter. It also gets stuck on fences, trees, towers or buildings and any animal might get tangled and suffocate to death.
All over the world, tiny pieces of plastic, either particles, fibers, or microbeads have flowed into the rivers and oceans, getting into marine and freshwater lives. Scientists have found microplastics in 114 aquatic species [5]. They are trying to determine what that means for human health. So far science lacks evidence that microplastics are affecting fish at the population level. Our food supply doesn't seem to be under threat, but enough research has been done now to show that the fish and shellfish we enjoy are suffering from the omnipresence of this plastic. Over 5 million tons of plastic flow from coastal areas into our oceans [6].

There are several negative health effects of breathing microplastics in human relating respiratory system including coughing, mucus production, damage of lung tissue, asthma, even cancer. The tiny particles of microplastics once inhaled into lungs, they cause injury in the respiratory systems. These particles, especially the smallest ones, can also flow into the bloodstream and cause cardiovascular and cerebrovascular diseases, which possibly cause cancer and affect the human immune and nervous system. Microplastics found in lung tissue show the inability of the body to get rid of all particles which means microplastics are bio-persistent [7].

How can plastic enter our body? There are five possible ways that plastics can get into our body and ruin human health.

\section{We eat plastic contaminated seafood}

The United Nations Food and Agriculture Organization stated that people are likely to consume negligible amounts of microplastics contained in seafood. However, there is concern about the human-health impacts of marine plastics. It is quite clear that this cannot possibly be a good addition to our diets. As we consume more and more contaminated seafood every day, this plastic pollution can affect our health as toxic content in plastic, such as lead, cadmium, and mercury will damage our body organ functions.

\section{We consume plastic via packaging}

BPAs are present in many plastic objects that come in direct contact with food, including plastic packaging, kitchenware and the inner coatings of beverages. BPA is metabolised in the liver to form Bisphenol A and it exits our body through our urine. BPA has been found in the urine of $95 \%$ of Canadians. The main problem is that BPA is an endocrine disruptor. The human endocrine system regulates a number of essential body functions including metabolism, heart rate, digestion and fertility.

\section{We drink microplastics via bottled water}

The World Health Organisation (WHO) published research in 2018 which exposed the presence of microplastics in $90 \%$ of bottled water which had been tested, only 17 were free of plastics out of 259. Today while there is not enough evidence on the impact of microplastics on human health, most scientists agree that it is an emerging area of concern and that if thousands of species worldwide are dying because of it, it can't be that good for us either. 


\section{We absorb plastic through our clothes}

According to the Global Apparel Fiber Consumption studies, out of $100,000 \mathrm{~kg}$ of fibers consumed worldwide in each year, $70 \%$ are synthetic. Synthetic fibers such as nylon, polyester, rayon spandex, acrylic, and acetate are derived from petroleum and are a type of plastic. Synthetic fabrics, accounting for about $60 \%$ of the material in our clothes worldwide, can release harmful toxic chemicals, such as silicone wax, heavy metals, and flame retardants, to our skin. Our skin is the largest and most permeable organ in our bodies and can absorb up to $60 \%$ of the substances we put in direct contact with it. Furthermore, synthetic fabrics do not allow skin to breathe and acting as a perfect environment for bacteria to grow. Toxic chemicals and microplastics released into waterways and ocean through our washing and household water waste also lead to plastic pollution in a subtle but expansive way. It is possible that a single load of laundry could release up to thousands of microfibers from our clothes into the water supply.

\section{We breathe plastic}

In the area where the waste management is ineffective or not existing, people often have no choice but to burn their trash in the open air. This common practice can be a great source of toxic fume which is released into the air and damage our respiratory system. A report in 2018 shows that 5 billion people globally live without waste collection or controlled waste disposal. Thus, most of waste goes to incinerators which has been proved releasing dioxin, one of the most toxic chemicals, in huge amounts into the air. Its residue, toxic ashes, can form in toxic ashes that can leak into land, water, and air.

Human health impacts of plastic have focused on specific stages in the plastic lifecycle, usually on single products, processes, or exposure pathways. This approach fails to recognize that significant, complex, and intersecting human health impacts occur at every stage of the plastic lifecycle, from waste management to ongoing impacts of microplastics in the air, water, and soil. A solution to the plastic crisis must address the full lifecycle [8]. (see figure 1)

However, plastic bag bans imposed by many governments witnessed a fall in plastic use. All countries claimed to have achieved or gotten closer to reaching their waste reduction goals but the impact of these bans does not end with the measurable reduction in plastic circulation. These alternatives ensure a fall in plastic pollution but affect other forms of environmental damage. Essentially, they replaced plastic with plastic. Although this alternative is likely to have a higher lifespan, it will still contribute to the plastic problem in the long-run because of its ineffective recycling system. Additionally, a majority of the bans have been imposed without a sufficient notice period. Thus, we cannot say that the plastic bag ban is one of the most effective solutions to plastic problems.

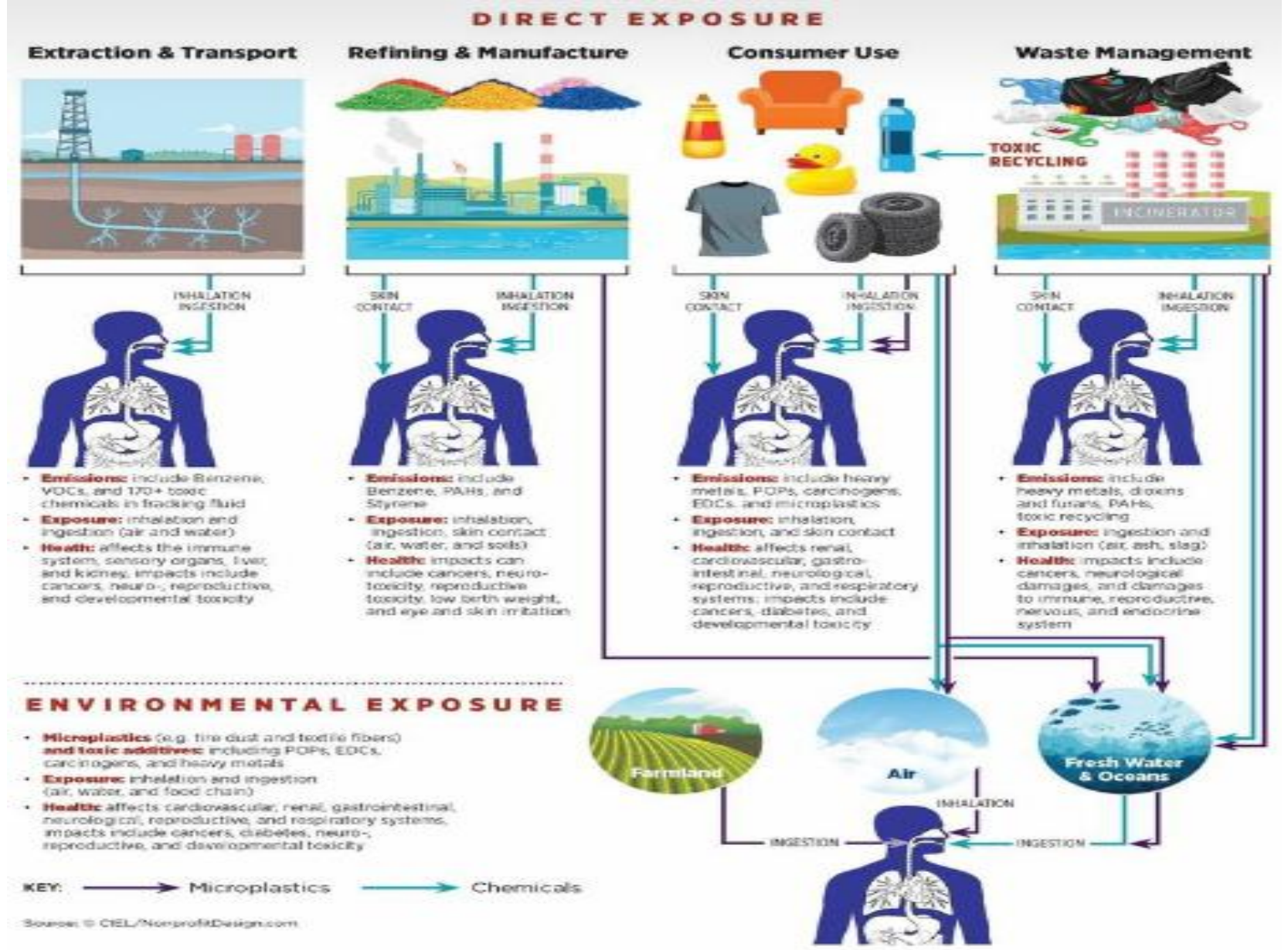

Figure 1. How humans are exposed to a large variety of toxic chemical and microplastics [9] 


\section{Mindful Mindset}

Mindset and mindfulness have been talked about greatly among those in education. Mindset is a set of belief introduced by Carol S. Dweck, which affects how one thinks, feels, and behaves. It is habitual ways of thinking. According to Dweck, people with growth mindset believe they can make change and achieve their goals in study, work, or relationship. On the contrary, those with fixed mindset believe that they will never make things better nor achieve their goals. For short, mindset refers to belief one has about oneself and his potential [10].

Mindfulness refers to active attention to one's present thought, feeling, body sensation, and environment [11]. In other words, mindfulness can turn one into an observer of one's own thought and belief about oneself, others, and world which means environment and eco-system. In Buddhism, mindfulness, sati, means to maintain awareness of reality [12]. It also refers to an awareness of things in relation to things and awareness of their relative value [13]. Mindset and mindfulness are valuable framework and they can complement each other in shaping consumer behavior and influencing consumers to make decision with care of themselves, others, and environment.

Mindful mindset can be a conceptual framework that influences consumers to make decision upon their contentment with care of others and environment when consuming. With mindful mindset, consumers will not only care for themselves nor respond only to their desires and needs, but they will make decision which are beneficial for their community and environment [14]. In the dilemma of which traditional goal of corporations is to maximize their profits [15] and the problems of overconsumption concerning limited resources and environmental sustainability have received little attention [16], mindful mindset can play a critical role in mediating between overconsumption and ignorance of environmental sustainability. Mindful mindset will promote awareness of environmental conservation and reduce the degree of overconsumption. Thus, consumption with mindful mindset can lead to sustainability.

\section{Mindful Consumption}

Consumption is known as a driving force of the global economy, however, it rests on the use of the natural environment and resources in a way that continues to have destructive impacts on the planet [17]. Although there is some concern about environmental problems and people are likely to buy more green products as they believe they are taking part in minimize environmental problems and bringing more sustainability, they may never realize that too much consumption can cause problems. Even their purchase becomes more eco-friendly, constantly rising in consumption could bring harm to the environment at the level that violates the sustainability [18]. Excessive consumption, mindlessly consuming without awareness of problems, can be the root of waste and pollution generation, decline of natural sources, and unsustainability.

Mindful consumption, consumption based on mindful mindset, is considered as a new wave of consumer behaviour. Moreover, as many societies are increasingly educated and financially sophisticated, they have the potential to further the trend of mindful consumption in everyday living while, at the same time, contributing towards sustainable future. The idea of mindful consumption derives from a mindset of awareness and attention that reflects receptivity to and engagement with the present moment, including a sense of care toward the self, community, and nature, which reinforces temperance in consumption practices that are both private and public in nature. A focus on mindful consumption can be valuable in aligning consumer self-interests to be free from unrewarding and unsustainable patterns of consumption. Mindfulness has the potential to lead to sustainable consumption by encouraging practices that heighten people's sense of awareness, whereby greater awareness of both the self and the ecosystem. It can serve to dampen the effects of unsustainable practices, such as overconsumption and deviant consumption, thereby fostering more sustainable outcomes [19]. (as figure 2)

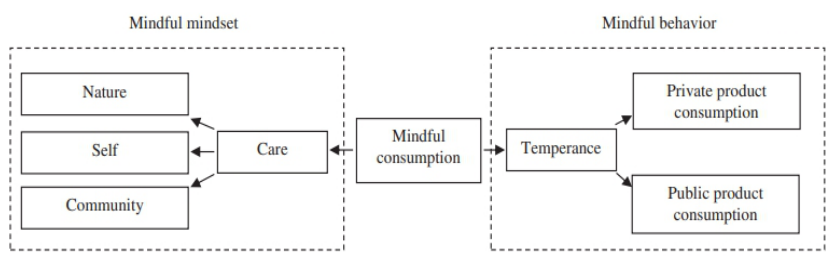

Figure 2. A model for mindful consumption [20]

With care of self, consumers focus on wellbeing and happiness rather than increasing materials. Caring for community, consumers value relationship in their community more than material possession. And caring for nature relates to taking actions to conserve environment and nature. With these practices in mind, consumers will consume moderately, avoid the pattern of purchase-throw away-and purchase again, as well as cease to consume in a competitive or comparing way. Hence, the problems of waste, plastic and other materials, will be solved at root. Mindful consumption can lead to reduction of waste, pollution, and resource extraction as well as promote sustainability. Consumer behavior with respect to sustainable consumption practices can be explained in a combined application of responsible consumption, anticonsumption, and mindful consumption theoretical perspectives in an integrated conceptual model for sustainable consumption [21]. (as figure 3).

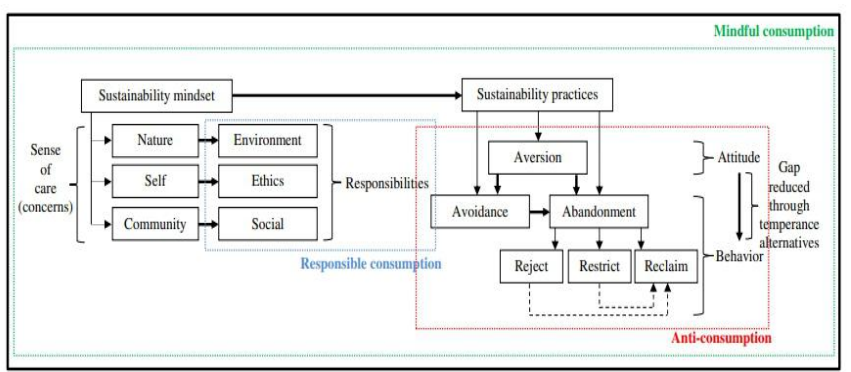

Figure 3. Integrated model for sustainable consumption [22]

Consumption has emerged as a key priority area in research and policy-making related to sustainable development. It is essential to understand mindful consumption concept as 
consciousness in thought and behavior about the implications and consequences of consumption. The main elements of mindful consumption are mindful mindset and mindful behavior [23]. Mindful mindset comprises a sense of caring and thinking about the future and the consequences of one's actions toward oneself, community, and nature, while mindful behavior involves behaving and making decisions with the aim of increasing a consumer's personal, economic, and social well-being to an optimal level. The major of the world's population often experiences underconsumption or overconsumption and its negative effect on personal and social well-being.

One of the earlier conceptual proposal on how mindfulness might be able to contribute to sustainable consumption comes from Rosenberg who sees a twofold contribution of the cultivation of mindfulness: By enhancing awareness of "potentially accessible cognitive-behavioral processes underlying consumption that have become relatively automatic" [24]. Mindfulness would allow for more deliberate choices. Additionally, mindfulness might re-instill a sense of interconnectedness and interrelatedness between people as a genuine (or synergetic), non-consumerist satisfier of the need for fulfillment. Mindfulness might be a supporting factor in achieving greater personal well-being and more ecologically sustainable lifestyles at the same time. More recently, there has been a discussion on how mindfulness could change our consumption patterns and it is agreed that mindfulness could positively influence consumers' awareness of their own consumption habits and strengthen non-materialistic values in life, leading to reduced aspirations to consume.

\section{Conclusion}

From 1950 to 2015, primary and secondary (recycled) plastic waste was cumulated to 6,300 Mt. Around 4,900 Mt, $60 \%$ of all plastics ever produced, were discarded and are accumulating in landfills or in the natural environment. Research into the environmental impacts of these microplastics in marine and freshwater environments has accelerated in recent years, but little is known about the impacts of plastic waste in land-based ecosystems. Many governments, especially in developed countries, are striving for well-designed and tailor-made management strategies to solve plastic waste and pollution problems. Strategies, such as substitution, reuse, material recycling, waste-to-energy, and conversion technologies have been adopted, but none of them completely overcomes the environmental challenges posed by the enormous and sustained global growth in plastics production and use.

Although the plastic bag bans managed to achieve their targets and there is more eco-friendly consumption today, constant rise in consumption could bring harm to the environment at the level that violates the sustainability. Hence, preventing plastic waste before it is generated could be considered as a practical way to plastic waste reduction. Mindful mindset, a conceptual framework, will influence consumers to make decision upon their contentment with care of others and environment when consuming. Mindful mindset can play a critical role in mediating between overconsumption and ignorance of environmental sustainability. It will promote awareness of environmental conservation and reduce the degree of overconsumption which leads to waste generation.

With care of self, others, community, and nature in mind, consumers will consume moderately, avoid the pattern of purchase-throw away-and purchase again, as well as cease to consume in a competitive or comparing way. Hence, the problems of waste, plastic and other materials, will be solved at root. Mindful consumption can lead to reduction of waste, pollution, and resource extraction as well as promote sustainability. Mindful consumption can play a critical role in reducing waste at source in this challenging time. When individuals realize that they can take part in minimizing plastic pollutions and contribute to sustainable environment, our communities, regions, and world can be more sustainable for the next generations

\section{References}

[1] Levi, G.P. \& Jonathan M. (2018) Cullen, Mapping Global Flows of Chemicals: From Fossil Fuel Feedstocks to Chemical Products. Environmental Science \& Technology. 52 (4): 1725-1734.

[2] MESAB (2018). The Circular Economy: A Powerful Force for Climate Mitigation. Stockholm: Material Econpmics Sverige $\mathrm{AB}$.

[3] Levi, G.P. \& Jonathan M. (2018) Cullen, Mapping Global Flows of Chemicals: From Fossil Fuel Feedstocks to Chemical Products. Environmental Science \& Technology. 52 (4): 1725-1734.

[4] Crippa, M. \& et al. (2019). A Circular Economy for Plastic: Insights from research and innovation to inform policy and funding decisions. Luxembourg: European Commission

[5] Royte, E. (2018). We Know Plastic Is Harming Marine Life. What About Us? Retrieved 28 July 2020, from https://www.nationalgeographic.com/maga zine/2018/06/ plastic-planet-healthpollution-waste-microplastics/

[6] Luo, K. (2018). Are you breathing plastic air at home? Here's how microplastics are polluting our lungs. Retrieved 28 July 2020, from https://www.weforum.org/ agenda/2018/06/microplastic-pollution-inair-pollutes-our-lungs

[7] Azoulay, D. \& et al. (2019). Plastic \& Health: The Hidden Costs of a Plastic 
Planet. Retrieved 28 July 2020, from https://www.plasticpollutioncoalition.org/b $\log / 2019 / 2 / 20 /$ report-plastic-threatenshuman-health-at-a-global-scale

[8] https://www.ciel.org/wpcontent/uploads/2019/02/Plastic-andHealth-The-Hidden-Costs-of-a-PlasticPlanet-February-2019.pdf

[9] https://www.mindheartspace.com/post/2016/07/17/mindset-vs$\underline{\text { mindfulness }}$

[10] https://katrinamurphycoaching.com/minds et-vs-mindfulness/

[11] Sharf, Robert (October 2014). "Mindfulness and Mindlessness in Early Chan", p. 942

[12] Gethin, Rupert M.L. (1992), The Buddhist Path to Awakening: A Study of the BodhiPakkhiȳa Dhammā. BRILL's Indological Library, 7. Leiden and New York: BRILL

[13] http://www.divaportal.org/smash/get/diva2:1110472/FULL TEXT01.pdf

[14] Hussain, W. (2012). Corporations, Profit Maximization, and the Personal Sphere. Economics and Philosophy, Vol. 28 (3).

[15] Sheth, J.N., Sethia, N.K., \& Srinivas, S.J. (2010). Mindful consumption: a customercentric approach to sustainability. Journal of the Academy of Marketing Science, 39 (1), 21-39. doi:10.1007/s11747-010-0216-3

[16] https://www.un.org/sustainabledevelopme $\mathrm{nt} /$ sustainable-consumption-production/

[17] Lim, M.W. (2017). Inside the sustainable consumption theoretical toolbox: Critical concepts for sustainability, consumption, and marketing. Journal of Business Research. 78. 69-80.

[18] Sheth, Jagdish N. \& et al. (2011), Mindful Consumption: A Customer-Centric Approach to Sustainability. Journal of the Academy of Marketing Science. 39: 2139.

[19] Rosenberg, E.L. (2005). Mindfulness and consumerism. in: Kasser, T. \& Kanner,
A.D. (Eds.). Psychology and consumer culture. The struggle for a good life in a materialistic world. American Psychological Assoc. Washington. pp. 107-125. 